\title{
O PROCESSO DE BOLONHA: UM ESTUDO DE CASO DE POLÍTICA PÚBLICA INTERNACIONAL (1999-2010)
}

\author{
Maurício Loboda Fronzaglia*
}

\begin{abstract}
Resumo: O presente artigo tem como objetivo analisar o Processo de Bolonha e a formação do Espaço Europeu de Ensino Superior como um estudo de caso de Políticas Pública Internacional. Para este fim, procede-se a uma análise histórica desse processo utilizando-se das teorias cognitivas das políticas públicas; a saber a teoria do referencial (sociologia política da ação pública) e a teoria dos três "Is" instituições, ideias e interesses. O artigo se constrói a partir das hipóteses de que é possível compreender as políticas públicas para além dos seus paradigmas nacionais e de que seus rumos são construídos a partir da interação dos atores nela envolvidos.

Palavras Chave: Processo de Bolonha, Espaço Europeu de Ensino Superior, Políticas públicas, políticas públicas internacionais.
\end{abstract}

The Bologna Process: A Case Study of International Public Policy (1999-2010)

Abstract: The purpose of this paper is to study the Bologna Process and the European Higher Education Area - EHEA, which can be considered an example of International Public Policy. This paper has been developed according to the cognitive approach of public policy: the referential theory (political sociology of public action) and the three "is" theory: institutions, ideas and interests. The hypothesis is that it is possible to understand public policy beyond its national paradigm. This article shows that the Bologna Process is a result from the regular interaction from its actors.

Keywords: Bologna Process, European Higher Education Area, Public Policy, International Public Policy.

* Graduado em Ciências Sociais pela FFLCH-USP, Mestre e Doutor pelo Departamento de C. Política do IFCH-UNICAMP. Professor da Universidade Presbiteriana Mackenzie. Pesquisador no Núcleo de Pesquisa sobre Qualidade de Vida/NPQV e no Núcleo de Análise da Economia Contemporânea/NAEC na mesma Universidade.

Recebido em: 30/10/2014 - Aceito em: 30/09/2015. 
El Proceso de Bolonia: Un estudio de caso de la Política Pública Internacional (1999 hasta 2010)

Resumen: Este artículo tiene como objetivo analizar el proceso de Bolonia y la formación del Espacio Europeo de Educación Superior como un estudio de caso de la Política Pública Internacional. Para ello, se procede a un análisis histórico de este proceso utilizando las teorías cognitivas de las políticas públicas; a saber, la teoría referencial (la sociología política de la acción pública) y la teoría de las tres "es" instituciones, ideas e intereses. El artículo se basa en la hipótesis de que es posible entender la política pública más allá de sus paradigmas nacionales y que sus caminos se construyen a partir de la interacción de los actores que participan en ella.

Palabras clave: Proceso de Bolonia, Espacio Europeo de Educación Superior, política pública, políticas públicas internacionales.

\section{Introdução}

Realiza-se, neste artigo, uma análise do Processo de Bolonha, e a consequente construção do Espaço Europeu de Ensino Superior, tomado como estudo de caso de uma política pública internacional. O problema central da pesquisa, da qual derivam outras perguntas específicas, é: seria possível analisar ações que ocorrem no cenário (sistema) internacional a partir das teorias das políticas públicas? As hipóteses norteadoras são: (1) o paradigma nacional, a partir do qual se estruturou o estudo das políticas públicas, mostra-se inadequado e necessita ser reassimilado de forma a dar conta das inúmeras variáveis internacionais que influenciam e condicionam, quando não determinam, a ação do Estado dentro das suas fronteiras nacionais e (2) a política pública internacional constrói seus objetivos e caminhos a partir da dinâmica de interação dos seus diversos atores.

O ponto de partida do artigo é minha tese de doutoradamento: "Políticas Públicas Internacionais: o caso do Processo de Bolonha" defendida em março de 2011 junto ao departamento de Ciência Política do Instituto de Filosofia e Ciências Humanas da Universidade Estadual de Campinas. Nele, defendi a tese de que se as políticas públicas, se entendidas como o Estado em ação, são mais do que as ações de política interna, elas também se desenvolvem, se originam e/ou são condicionadas pelo 
sistema internacional, sistema que, em muitas correntes teóricas, não são levadas em consideração nos modelos de análise das políticas públicas. Em tempos globalizantes as políticas públicas podem expressar uma dinâmica de interação que entrelaça o local, o nacional e o internacional; e nesse entrelaçar se constroem realidades para onde podem convergir teorias de relações internacionais e políticas públicas. $\mathrm{O}$ entrelaçar é o espaço das políticas públicas internacionais. O Processo de Bolonha e todo trabalho para a criação do Espaço Europeu de Ensino Superior (European Higher Education Area - EHEA) é um dos exemplos desse entrelaçar, do ponto de encontro entro o local, o nacional e o internacional.

Em sua primeira parte, esse artigo concentrar-se-á na definição do Processo de Bolonha, nas tentativas que o precederam e no contexto político do seu lançamento oficial, em 1999. A segunda parte se concentra na questão do problema da análise das políticas públicas no sistema internacional através do uso das abordagens cognitivas. Na terceira parte, analisa-se a evolução do processo pelas teorias cognitivas através do estudo dinâmica interativa dos atores utilizando-se, para isso, das Declarações oficiais dos Ministros responsáveis pelo Ensino Superior em cada um dos encontros ocorridos durante a primeira década deste século até se chegar a criação oficial do Espaço Europeu de Ensino Superior, em 2010. Finalmente, seguem-se as conclusões.

\section{1 - O Processo de Bolonha: antecedentes e seu lançamento}

O Processo de Bolonha é uma iniciativa dos governos dos Estados europeus, em conjunto com as suas universidades, a comunidade acadêmica e suas organizações de classe, para a integração dos sistemas de ensino superior, das instituições, estudantes e professores dos países participantes para a construção de uma integração europeia do ensino superior. Conta, para isso, com o apoio e parceria de instituições internacionais europeias, incluindo a própria União Europeia. 
Embora possa ser visto como a transposição da ideia de integração regional para a esfera específica do ensino superior, o Processo de Bolonha pode, antes, ser visto como uma política pública internacional porque, como será demonstrado, desenvolveuse inicialmente a partir da ação dos Estados envolvendo posteriormente atores locais, nacionais e internacionais que interagem em uma dinâmica de construção de uma ação pública que perpassa e interliga os níveis locais, nacionais e internacional.

O objetivo colocado pelos membros do Processo de Bolonha foi a construção efetiva do Espaço Europeu de Ensino Superior (EHEA - European Higher Education Area, lançado em 2010) ${ }^{1}$ implementando-se a harmonização das estruturas educacionais, jurídicas, normativas e institucionais dos sistemas nacionais de ensino superior a fim de garantir a livre circulação de estudantes e professores entre as universidades dos países participantes. Desta forma, além da maior integração, buscou-se também reforçar (ou retomar) a atratividade e o vigor do ensino superior europeu visà-vis a concorrência com as universidades da américa do norte e da China. Atualmente são 50 os Estados membros do EHEA², e constam como membros consultivos, o Conselho Europeu, a UNESCO, a European University Association - EUA, a European Associationn of Institutions in Higher Education - EURASME, a European Students Union - ESU, a European Association for Quality Assurance in Higher Education - ENQA, a Education International Pan-European Structure e a Businesseurope. Cada uma das instituições consultivas desempenha um papel distinto

\footnotetext{
${ }^{1}$ http://www.ehea.info/article-details.aspx?ArticleId=3. Acesso em 01/06/2015

2 Albânia, Alemanha, Andorra, Armênia, Áustria, Azerbaijão, Bélgica (Flemish Community e French Comunity), Bósnia, Bulgária, Cazaquistão, Croácia, Chipre, República Tcheca, Dinamarca, Eslováquia, Eslovênia, Espanha, Estônia, European Comission, Finlândia, França, Geórgia, Grécia, Holanda, Hungria, Irlanda, Islândia, Itália, Letônia, Liechtenstein, Lituânia, Luxemburgo, Macedônia, Malta, Moldávia, Montenegro, Noruega, Polônia, Portugal, Reino Unido, Romênia, Rússia, Sérvia, Suécia, Suíça, Turquia, Ucrânia e Vaticano.
} 
na dinâmica e interação que marca a construção e o funcionamento do Processo de Bolonha, como será visto posteriormente. Ressaltase, neste ponto, que todas essas instituições, que surgiram e se desenvolveram de forma paralela e complementar ao processo de integração regional europeu, adquirem um papel mais relevante a partir das suas participações como atores nas ações de formulação e implementação do EHEA.

\section{1 - Iniciativas anteriores}

O Processo de Bolonha não se configura como a primeira tentativa de estabelecer um espaço comum de ensino superior no continente europeu, apoiado na ideia de equivalência e harmonização dos créditos e diplomas. Segundo SerbanescuLestrade (2009) há 3 convenções assinadas pelo Conselho da Europa já nos anos 1950 prevendo a equivalência dos diplomas e da admissão nas instituições de ensino superior. Esse é o período de início da construção da União Europeia e as possibilidades levantadas para a construção da integração regional eram inúmeras e mais abrangentes do que a própria integração acabou por se realizar. Durante os anos 1970 houve a criação do Joint Studies Programmes que previa uma maior mobilidade por parte dos estudantes e instituiu um processo de equivalência dos créditos universitários ${ }^{3}$. Ainda durante essa década foram estabelecidas as primeiras medidas para a o reconhecimento internacional dos diplomas no âmbito da União Europeia através de ações pontuais nos cursos de medicina, farmácia e odontologia. Foi também criado, no último ano dessa década, o programa EURYDICE ${ }^{4}$, uma rede de informações sobre a educação nos países europeus.

Contudo, as grandes mudanças no sistema de ensino superior europeu apenas aparecem concretamente no final dos anos

${ }^{3}$ Esse programa foi incorporado ao ERASMUS durante a década de 1980 (SERBANESCU-LESTRADE, idem).

${ }^{4}$ https://webgate.ec.europa.eu/fpfis/mwikis/eurydice/index.php/Main_Page . Acesso em 15/06/2015. 
1980, com a criação do programa ERASMUS 5 cujo objetivo inicial era a promoção da mobilidade dos estudantes e no consequente reconhecimento mútuo das formações superiores. O programa marca o nascimento de projetos ambiciosos como a criação de uma rede universitária europeia, de bolsas internacionais de estudo e reconhecimento acadêmico (SERBANESCU-LESTRADE, IDEM). Durante os anos 1990, estabeleceu-se o Sistema Europeu de Créditos Transferíveis - ECTS ${ }^{6}$, que tem o objetivo de funcionar como uma espécie de "moeda única" entre as instituições europeias de ensino superior participantes. Esse sistema leva em conta a carga horária dos cursos e a carga de trabalho dos estudantes e acabará por se configurar como uma ferramenta essencial para o estabelecimento do Espaço Europeu de Ensino Superior.

Se as primeiras convenções assinadas quando do início da União Europeia soaram, à época, mais como intenções gerais do que como diretrizes concretas, foi a partir delas, e do próprio desenvolvimento da integração regional, que as demais iniciativas surgiram e acabaram por criar a referência que será colocada em prática a partir do Processo de Bolonha. Elas se caracterizam como o aprendizado social a partir do qual se elabora e se realiza a política pública que a sucede. Elas foram a expressão, e também expressaram, os momentos da construção da integração regional e da internacionalização da esfera política e das políticas públicas de ensino superior (FRONZAGLIA, 2011).

\section{2 - O contexto político-social do lançamento do Processo de Bolonha}

A longa história das universidades europeias desenvolvese em vínculo estreito com a religião cristã e encaixava-se na funcionalidade da sociedade medieval. Caracterizavam-se como autônomas cujo custeio provinha das suas propriedades ou de

5 http://ec.europa.eu/programmes/erasmus-plus/index_pt.htm. Acesso em 15/06/2015.

${ }^{6} \mathrm{http}: / /$ ec.europa.eu/education/ects/ects_fr.htm . Acesso em 15/06/2015. 
pagamentos feitos pelos estudantes, ainda que sob a proteção da Igreja ou dos Monarca. Adquirem uma nova identidade, e novas funções, a partir do século XIX com a consolidação dos estados nacionais europeus. As universidades outrora privadas passam as mãos do Estado e passam a ter novas funções em consonância com a nascente sociedade moderna e industrial. Assumem características distintas de acordo com as características e desenvolvimento das sociedades nas quais se encontram inseridas. É possível separá-las em três modelos básicos: o alemão, mais voltado para o desenvolvimento da pesquisa como principal atividade, o francês, voltado para a formação de quadros de administração do Estado e o anglo-saxão, onde as universidades privadas desempenham um papel de formação de profissionais qualificados para a, então, nova configuração social industrial (HORTALE e MORA, 2004). Essas características mostram o quão importante é a configuração nacional na identidade do ensino superior europeu. Tal configuração será gradualmente atenuada em busca da criação de uma identidade europeia que se faz através do Processo de Bolonha. Por estarem fortemente arraigadas, como a própria noção de nacionalidade, as ações previstas e desejadas quando da própria formação da União Europeia apresentam uma evolução diferente daquela outrora imaginada. Ainda que a integração universitária apresente fortes vínculos condicionantes com a integração institucional, ela se consolida fora do âmbito da União Europeia e por iniciativa dos líderes políticos nacionais e não da própria comunidade acadêmica.

De fato, pode-se colocar como marco do início do Processo de Bolonha o encontro acontecido entre os ministros de estado responsáveis pelo ensino superior da França, Claude Allegre, da Itália, Luigi Berlinguer, do Reino Unido, Tessa Backstone e da Alemanha, J. Ruettgers por ocasião da celebração do $800^{\circ}$ aniversário da Sorbonne, realizado em maio de 1998. Os quatro ministros assinam a "Déclaration de la Sorbonne" (1998), redigida pelo ministro francês, onde se colocam as diretrizes para a construção de uma integração europeia que ultrapasse o âmbito econômico e financeiro e que se construa uma "Europa do Saber", 
que se adeque aos novos desafios lançados para a educação. A maioria dos pontos defendidos ali constam do plano de educação lançado pelo predecessor de Claude Allegre, François Bayrou, em 1997, para uma reforma europeia do ensino superior levando em consideração: a equivalência dos aprendizados da graduação e o estabelecimento de padrões curriculares comuns. Allegre substitui Bayrou por indicação do então novo primeiro ministro francês, Lionel Jospin, no final daquele ano e dá continuidade as propostas apresentadas por esse último. Desta forma, a base do que viria a ser o Processo de Bolonha foi o resultado de uma "iniciativa improvisada" (SERNASCU-LESTRADE, IDEM) do ministro francês que contou o apoio de seus colegas da Itália, Reino Unido e Alemanha.

\section{3 - O Início Ofical do Processo de Bolonha}

Após pouco mais de um ano da "Déclaration de la Sorbonne", acontece o encontro que oficializa o lançamento do Processo de Bolonha, ocorrido nesta cidade italiana, e expõe seu objetivo de construção de um espaço europeu de ensino superior. Participam e assinam a Declaração de Bolonha 31 membros de 29 países $^{7}$. Foram ali estabelecidas as metas que vieram a orientar as ações do Processo de Bolonha.

A partir da Conferência e da Declaração de Bolonha, o processo adquire a seguinte dinâmica de funcionamento; reuniões dos Ministros responsáveis pelo Ensino Superior dos países membros a cada dois anos quando são atualizados ou modificados os objetivos primeiros colocados, com relatórios de acompanhamento dos trabalhos realizados durante o intervalo

\footnotetext{
7 São eles: Alemanha (dois representantes), Áustria, Bélgica (dois representantes, uma para a região de Flandres e outro para representar a região da Valônia), Bulgária, Estônia, Dinamarca, Eslováquia, Eslovênia, Espanha, Finlândia, França, Grécia, Holanda, Hungria, Irlanda, Islândia, Itália, Letônia, Lituânia, Luxemburgo, Malta, Noruega, Polônia, Portugal, República Tcheca, Reino Unido, Romênia, Suécia e Suíça.
} 
dos encontros e análise de possíveis modificações e novas propostas que acabam por surgir em consequência da dinâmica de desenvolvimento do próprio Processo de Bolonha. Os encontros se repetem nessa periodicidade até o ano de 2009, quando é feito um encontro logo no ano seguinte que marca a criação institucional do Espaço Europeu de Ensino Superior. Cada encontro produz uma Declaração que sintetiza os progressos e nossos desafios colocados para o desenvolvimento dessa política pública internacional. Foram realizados os seguintes encontros e declarações:

QUADRO 1 - Encontros e Declarações que marcam o Processo de Bolonha até o lançamento do EHEA

\begin{tabular}{|c|c|}
\hline Local & Data \\
\hline Encontro e Declaração de Bolonha & 1999 \\
\hline Encontro e Declaração de Praga & 2001 \\
\hline Encontro e Declaração de Berlin & 2003 \\
\hline Encontro e Declaração de Bergen & 2005 \\
\hline Encontro e Declaração de Londres & 2007 \\
\hline Encontro e Declaração de Leuven et Louvain-la-Neuve & 2009 \\
\hline Encontro, Declaração e Lançamento do EHEA - Budapeste-Viena & 2010 \\
\hline
\end{tabular}

Fonte: Fronzaglia 2011.

Através do acompanhamento de cada uma das declarações feitas nesses encontros torna-se possível mapear a dinâmica de desenvolvimento que marcam o Processo de Bolonha. Torna-se possível perceber os conflitos e a construção dos consensos, tornase possível acompanhar a dinâmica de interação entre os atores envolvidos e a entrada de novos atores no processo de formulação dessa política pública internacional, tornar-se ainda possível mapear os interesses desses diversos atores, descrever a forma de atuação das instituições envolvidas e também as ideias e valores defendidos que acabam por formar o referencial sobre o qual se baseiam as discussões e decisões. Acompanha-se também tanto a 
evolução quanto as transformações e mudanças de intensidades das metas estabelecidas que norteiam o processo.

\section{2 - O Processo de Bolonha e as teorias cognitivas das políticas públicas}

A análise do Processo de Bolonha como uma política pública acarreta uma série de desafios metodológicos e epistemológicos do próprio campo das políticas públicas (e da ciência política). Em primeiro lugar, tratando-se de um fato que se desenvolve, também, no sistema internacional seria possível estuda-lo a partir do arcabouço teórico próprio das relações internacionais e, mais precisamente, a partir da definição de regimes internacionais. Pareceu-me, contudo, que sendo essa a escolha metodológica, perder-se-ia uma dimensão fundamental do fato: sua dinâmica de interação entre atores locais, nacionais e internacionais. Considerando-a como a característica singular do Processo de Bolonha, buscou-se na área das políticas públicas por abordagens que conseguissem capta-la em seus aspectos fundamentais.

O campo de estudo das políticas públicas apresenta uma vasta gama de abordagens teóricas, das análises ou sequenciais das Policy Sciences até as teorias cognitivas, passando pelas análises institucionais. $\mathrm{O}$ início do estudo das políticas públicas nos Estados Unidos tinha um claro objetivo: dar racionalidade e eficiência para as decisões do governo. Os primeiros estudos nessa área (Lasswell; 1956;1970) preocupam-se com a criação de modelos sequenciais que expressem a racionalização da ação estatal. Contudo a enumeração de uma sequência de ações que marquem as políticas públicas acarretará em uma série de questionamentos que dali derivam; como se estabelecem as agendas governamentais (Kingdon, 2002)? Como se realiza efetivamente a implementação das políticas públicas? Quais aspectos as influenciam e as delimitam (Mazmanian e Sabatier, 1983)? Como a estrutura institucional pode influenciar a ação dos mandatários eleitos (Scokpol, 1993)? 
Além dessas questões, outro desafio se coloca quando se constata que a análise das políticas públicas se encontra, em sua imensa maioria, delimitada pelo seu paradigma nacional (KOTT e DROUX, 2013). Contudo, a esfera internacional tem sido o cenário para o nascimento e implementação de muitas políticas nas mais diversas áreas, da mesma forma que essa esfera delimita as ações dos governos em seus próprios territórios. As ações das diversas organizações internacionais, o desenvolvimento da globalização econômica (e cultural) e os processos de integração regional são exemplos de como o sistema internacional perpassa a esfera nacional das políticas públicas ${ }^{8}$.

As indagações e questões expostas acima levaram-me a escolha das teorias cognitivas como abordagem metodológica para a compreensão do Processo de Bolonha. O que designo como teorias cognitivas das políticas públicas neste artigo compreende a sociologia política da ação pública (teoria do referencial) e a teoria dos três Is: Ideias, Instituições e Interesses.

\section{1 - A Sociologia Política da Ação Pública e a Teoria do Referencial}

A sociologia política da ação pública (também conhecida como teoria do Referencial) teve sua origem e desenvolvimento na França, através dos trabalhos de Pierre Muller e Bruno Jobert e tem como ponto de origem o livro "O Estado em Ação", lançado no final da década de oitenta do século passado. O desafio exposto pelos autores seria o de conseguir harmonizar, em uma mesma abordagem teórica, as pesquisas sobre as políticas e as reflexões sobre o Estado na sociedade contemporânea. Haveria um abismo entre essas duas linhas que seriam a expressão de diferentes tradições da ciência política: a prática anglo-saxã da análise

${ }^{8} \mathrm{O}$ uso de termos tais como "européanisation" (SAURUGGER, S. e SUREL,Y., 2006), "État Européen" (HASSENTEUFEL, P. e SUREL, Y. 2000). "Action Publique Européenne" (JACQUOT, S. e WOLL, C., 2008), e política pública européia, entre outros, são sinais claros dessa construção.

Idéias - Rev. Inst. Filos. Ciênc. Hum. UNICAMP, v.6, n.2, p. 59-100 jul/dez. 2015 
das políticas públicas e a filosofia política europeia. Seria então necessário reintegrar a análise das políticas em uma concepção mais ampla das relações entre Estado e sociedade de forma que as teorias de Estado se beneficiassem das conquistas na área das políticas públicas (1987). Não é por um simples acaso que o nome do livro seja também a definição dadas pelos autores para designar as políticas públicas: elas são o Estado em ação.

O estudo do Processo de Bolonha evidencia a importância desses questionamentos visto que não seria possível analisalo sem se referir, mesmo que de forma sintética, as reflexões sobre o próprio Estado. Tomá-lo como exemplo de política pública internacional significa partirmos do "Estado em ação" identificarmos as interações entre diversos atores que ocorrem no cenário internacional e que se concretizam nacionalmente e localmente através, mas não apenas, da ação dos seus atores principais. $\mathrm{O}$ "Estado em ação" se expressa, assim, na realização das políticas públicas em seus fundamentos e em sua sequência de implementação para além das fronteiras nacionais ${ }^{10}$.

Segundo essa abordagem as políticas públicas (Estado em ação) se realizam dentro dos limites de regulação (das relações políticas, econômicas e sociais) e legitimação (do seu próprio poder

9 Jobert e Muller definem o "Etat en action" como "un Etat dont le fonctionnement est structuré autour de la conduite des politiques publiques» $(1987,10)$. O funcionamento do Estado se estrutura no entorno da condução das políticas públicas, assim quando faço referência as políticas públicas que se originam fora dos limites de ação do Estado, o significado da sua ação deve ser reavaliado nesse ponto específico porquê da sua ação depende a concretização das ações definidas na esfera internacional.

${ }_{10}$ Segundo Hassenteufel (2008), os componentes principais presentes em todas as políticas públicas: são seus fundamentos (seus objetivos), seus instrumentos de ação e o público alvo. Esses componentes acabam, também, por corresponder a sequência chave das políticas públicas, a saber: definição e entrada na agenda política dos problemas sobre o quais o Estado agirá, a adoção de decisões e sua implementação e execução. Considera-se ainda, como outro elemento sequencial, a posterior avaliação da política pública. 
e objetivos) buscados pelo próprio Estado (JOBERT, 2004) ${ }^{11}$. Essa relação dialética entre o regular e o legitimar define o contexto institucional das políticas públicas. Aqui o Estado não é visto como um ator homogêneo e coerente capaz de impor uma vontade coerente à sociedade para seu próprio bem-estar, pelo contrário, é considerado como máquina estatal agindo muitas vezes de forma irracional, muitas vezes conflitante e poucas vezes age como um ator unificado. As ações estatais expressam essas características e contradições. A racionalidade da ação pública é instrumentalizada por interesses e atores diversos, inclusive os estatais, e se realiza condicionada pela sua própria estrutura institucional e jurídica. No caso aqui, considera-se o desenvolvimento da ação pública dentro de um cenário de interação entre os diversos atores em seus níveis locais, nacionais e internacionais. De fato, considera-se, segundo essa abordagem, que as políticas públicas são o resultado da interação de diversos atores dentro de um contexto político e valorativo específico expressando um equilíbrio que se mostrará provisório e que necessita de incessantes ajustes. Ou seja, as etapas de construção de uma política pública não se encontram dadas rigorosamente à priori, elas se definem e se redefinem segundo a interação dos atores envolvidos. A partir dessas observações Jobert e Muller (1987) apresentam três elementos chave de toda política pública: o primeiro é a relação setorial-global, o segundo é o referencial e por fim os atores que moldam e participam das relações de poder constituintes da política pública a ser implementada.

\footnotetext{
${ }^{11} \mathrm{O}$ "Estado em ação" se expressa, assim, na realização das políticas públicas em seus fundamentos e em sua sequência de implementação Segundo Hassenteufel (2008), os componentes principais presentes em todas as políticas públicas: são seus fundamentos (seus objetivos), seus instrumentos de ação e o público alvo. Esses componentes acabam, também, por corresponder a sequência chave das políticas públicas, a saber: definição e entrada na agenda política dos problemas sobre o quais o Estado agirá, a adoção de decisões e sua implementação e execução. Considera-se ainda, como outro elemento sequencial, a posterior avaliação da política pública.
} 


\subsection{2 - A relação setorial - global}

O primeiro elemento consiste na tentativa de ajuste entre esses dois níveis, o setorial, que diz respeito à área de desenvolvimento de uma política pública (nesse caso o setor do ensino superior) e o global, que se referem às ações do Estado (legitimação, integração, regulação e coesão social) visando à totalidade social. Essa relação não se encontra livre de contradições e equilíbrios provisórios, porque o próprio Estado traz em sua dinâmica interesses antagônicos entre os setores que o compõe e o influenciam nas tomadas de decisão.

No caso estudado, a relação setorial-global não se aplica somente aos arranjos internos, já que estes dependem das negociações e da dinâmica internacional de construção da ação pública específica. Desta forma, a relação setorial - global pode ser vista como a relação de um setor com a sociedade como um todo da mesma forma que pode também ser analisado como a relação de um tema específico e sua importância na esfera internacional; ou seja, global. Além disso, as políticas públicas, e por consequência a relação setorial - global, segundo uma perspectiva histórica, são dispositivos de autoreflexividade do Estado (MULLER, 2015). Isso quer dizer que a ação do Estado reflete sua própria concepção dos seus objetivos e do papel que representa em um período histórico específico. Assim as políticas públicas se pensam e devem ser analisadas segundo seus ciclos de ação. Os ciclos são um processo através do qual se desenvolve, se estabiliza e depois se fragmenta e se desagrega uma configuração global definindo o papel e o lugar das políticas públicas no funcionamento das sociedades (MULLER, 2015). Para cada ciclo de ação se desenvolvem diferentes regimes de atividades econômicas, de cidadania e de políticas públicas que refletem e são a reflexão (autoreflexividade) do referencial segundo o qual o Estado atua.

Muller identifica quatro ciclos históricos: o primeiro é o ciclo do Estado Liberal Industrial, àquele que se consolida a partir das primeiras revoluções industriais e se mantém durante todo o século XIX até as primeiras décadas do século XX, suas 
atividades econômicas decorrem dentro dos princípios liberais; a cidadania é marcada pelo início das conquistas dos direitos civis e políticos e os primeiros esboços de políticas sociais. Segundo ciclo, do Estado Providência, consolida-se, em modelos nacionais diferentes, a partir do final da segunda grande guerra e tem como características as políticas econômicas keynesianas, a consolidação dos direitos civis e políticos e a construção da estrutura de bemestar social. Já o ciclo do Estado Empresa se impõe no final do século XX, com a instituição de políticas econômicas neoliberais, com a intensificação da globalização e o questionamento dos investimentos sociais do Estado. Esse ciclo se expressa de forma mais clara na consolidação do Estado Regulador. Finalmente, há o ciclo da Governança Sustentável que estaria em processo de construção, marcado pelo paradigma do desenvolvimento sustentável, da governança e mesmo início das discussões de uma cidadania global ou transnacional e das políticas públicas internacionais. O Processo de Bolonha se realiza no momento de mudança do terceiro para o quarto ciclo.

\subsection{3 - O Referencial}

O segundo dos elementos chave, o chamado "referencial" define-se como o conjunto de normas e códigos que delimitam os parâmetros da ação do Estado. Podem-se considerar as normas jurídicas como parte do referencial, visto que estabelecem os limites legais de ação. As referências dizem respeito, também, as experiências anteriores na construção e implementação de uma política pública. A forma como a política pública se concretizava outrora se estabelece como parâmetro, quando não como paradigma, da ação pública, remetendo o referencial a questão da autoreflexividade do Estado. A cultura política de um país, seu ambiente institucional (a legislação, o direito de propriedade), os códigos de ética, os hábitos consolidados em regras e mesmo instituições informais são partes integrantes do referencial.

Chamado pelos autores (1987) o ato constitutivo de toda política, o referencial é resultado de uma construção social que 
abrange as interações, relações de poder e interdependência dos atores envolvidos nesse processo. Sua construção norteia as relações entre o Estado (e seus múltiplos atores) e os setores sociais envolvidos e influencia a forma como as decisões irão se institucionalizar. O referencial, no sentido aqui descrito, pode ser tomado como sinônimo de paradigma e ainda como resultado da aprendizagem social das políticas públicas que o precederam e o moldaram.

\subsection{4 - A Construção do Referencial}

O terceiro elemento chave é saber quem são os responsáveis pela construção do referencial, ou seja, os atores, suas origens, características, interesses, suas formas de interação, seu contexto cultural e seus valores. A partir do entendimento dessa construção que se torna possível desvendar as relações de poder que se encontram na política pública, a partir de quais referências se elaboram e qual o potencial de ação dos atores envolvidos. A construção do referencial não se expressa por uma dinâmica sequencial, mas sim uma dinâmica de rede, onde atores estão interligados e agem segundo referências mutuamente construídas. A construção também é condicionada pelo ciclo de ação no qual se encontra a sociedade estudada. Os ciclos identificados e definidos por Muller (2015), como descritos anteriormente, condicionam a ação dos atores envolvidos e a própria construção do referencial.

Analisar a construção do referencial é também analisar a forma como uma política pública se implementa e se viabiliza. Para isso é preciso tentar compreender o sentido da ação dos atores e como eles se expressam e se reelaboram na dinâmica de interação da política. Patrick Hassenteufel (2008) descreve essa interação em termos de construção coletiva de atores políticos, experts, atores intermediários, atores estatais e não estatais e atores internacionais sem, contudo, esquecer que são relações políticas e relações de poder. Ademais, coloca-se que os interesses e as formas de ação dos atores pode variar de acordo com o cenário de atuação. Interesses 
e discursos podem se adequar aos cenários locais, nacionais e internacionais.

De acordo Yves Surel (2000) as políticas públicas são o resultado de interações sociais que ocasionam a produção de ideias, representações e valores comuns. E eles, por sua vez, acabam por definir a maneira como os atores enxergam os problemas públicos e como concebem as respostas a esses problemas. Valores e representações compartilhados não excluem a dimensão conflitiva da política pública, mesmo porque grupos sociais e de interesse distintos constroem e compartilham valores e ações que entram em conflito na ação política.

Torna-se importante nesse ponto de construção do referencial as chamadas narrativas das políticas públicas. Elas se caracterizam como a forma que reveste os elementos cognitivos ligados a uma determinada política pública. Segundo o mesmo autor "as narrativas de políticas públicas tornam os problemas sociais compreensíveis e acessíveis à ação humana. De forma característica, sugerem uma série de ações ao invés de outras estabelecendo uma ligação entre o presente e o futuro" (RADAELLI, 2000, 257). Considerando-se a dinâmica do Processo de Bolonha é possível notar que essa política pública internacional se desenvolve como uma trama de interações e interesses, de atores públicos e privados, nacionais, locais e internacionais, embasados em valores e percepções cognitivas construídas ao longo do processo, dotanto, assim, essa narrativa de projeção futura e explicando o presente. Por essa razão o artigo se debruça nos documentos emitidos pelos encontros dos Ministros responsáveis pelo ensino superior ${ }^{12}$. Esses relatos são expressões explicativas do presente e indicativas de como o processo se constrói.

${ }^{12} \mathrm{Na}$ tese foram analisados não só os documentos referidos acima como também os comunicados do órgão representativo das universidades europeias (EUA - European University Association) e dos estudantes (ESU - European Students' Union).

Idéias - Rev. Inst. Filos. Ciênc. Hum. UNICAMP, v.6, n.2, p. 59-100 jul/dez. 2015 


\section{2 - A teoria dos três "Is"}

A importância aqui expressa dos valores e representações, dos contornos legais e do comportamento fragmentado do Estado e, por consequência, dos conflitos de interesse nos leva a uma outra abordagem cognitiva das políticas públicas: a Teoria dos Três "Is". Interesses, instituições e ideias complementam a noção de referencial, das relações de poder e da relação global setorial. Instituições dizem respeito, em primeiro lugar, ao Estado e toda sua estrutura de poder e funcionamento, seja em suas diversos áreas de atuação, seja em suas diversas e autônomas esferas de atuação, seja na divisão dos poderes. As instituições representam as "regras do jogo" e criam um sistema de incentivos (muitas vezes contraditórios) para tomada de decisão dos atores. No caso do Processo de Bolonha há uma interação entre instituições locais, nacionais e internacionais que se relacionam.

Os interesses, indissociáveis das instituições, envolvem os objetivos de cada instituição e de cada ator envolvido no processo. Nesse ponto os interesses também se condicionam pelas arenas onde são construídos, se localmente, nacionalmente ou internacionalmente. As ideias são as imagens e representações coletivas, são os valores expressos nas ações dos atores. Elas formam o contexto e influenciam o comportamento dos atores e formam também os contornos no qual se encaixa e se elabora, constantemente, o referencial. De acordo com Surel e Palier (2005), mobilizar conjuntamente os três "Is" funda-se na ideia de que as variáveis componentes e explicativas de uma política pública não são exclusivas, elas se entrelaçam, e se associam de forma a delimitar a dinâmica de ação dos atores, algo essencial para a compreensão do Estado em ação.

Interesses, instituições e ideais complementam os elementos chave identificados pela sociologia política da ação pública. A relação setorial-global é um exemplo do entrelaçamento dos três "is" a partir do Estado em ação porque expressa os interesses dos atores envolvidos, suas relações institucionais e as ideias que se enfrentam na implementação de uma política pública. O referencial 
se faz também pelo entrelaçamento das diversas dimensões dos três "is" e dos atores que, constantemente, o formatam.

\section{3 - O Processo de Bolonha: análise do seu desenvolvimento}

Analisa-se, nesta seção, o Processo de Bolonha como estudo de caso de políticas públicas internacionais através das declarações feitas pelos ministros responsáveis pelo ensino superior nos sete encontros que marcam seu desenvolvimento até o lançamento do Espaço Europeu de Ensino Superior, de acordo com os parâmetros acima expostas das teorias cognitivas das políticas públicas. As políticas públicas internacionais são processos dinâmicos de ação pública que, definem-se, primeiro, por sua gênese que tem lugar no cenário internacional, em segundo lugar, por seus objetivos internacionais de implementação, e, ainda, por sua dinâmica transnacional de construção e mudança do referencial, pela participação de atores locais, nacionais e internacionais e, finalmente, por sua necessidade de concretizar suas ações e normatizações em nível nacional através da ação do Estado em interação com outros atores.

\section{1 - Declaração de Bolonha de 1999}

O encontro que lançou oficialmente o Processo de Bolonha (e ocorrido na mesma cidade que o nomeia) tornou público os seus objetivos e contexto através de uma declaração oficial (Déclaration de Bologne, 1999) assinada pelos ministros responsáveis pelo ensino superior dos 29 países ali participantes. A declaração referese a extraordinária "construção europeia" (1999) que se realiza pelo esforço da União Européia de dos seus cidadãos e que tece ligações estreitas entre seus membros e demais estados do continente aportando em uma realidade de novas dimensões que direcionam para a necessidade de uma Europa "mais completa e ambiciosa"

reforçando as esferas culturais, sociais, intelectuais e científicas da integração que constituem a Europa dos Conhecimentos. 
O documento reforça as diretrizes já expostas na Déclaration de la Sorbonne de 1998 sobre o papel a ser desempenhado pelas universidades no desenvolvimento da Europa dos Conhecimentos através da criação de um espaço comum de ensino superior que favorece a intensificação dos laços da integração regional. De fato, as universidades europeias já haviam se manifestado sobre tal necessidade na Magna Charta Universitatum, de 1988, onde defendiam sua independência e autonomia com garantias da capacidade dos sistemas de ensino superior e de pesquisa para se adaptarem as demandas da sociedade e do avanço científico, configurando mais um fato que formará o referencial de aprendizagem social dessa política pública internacional.

Reconhecendo a contribuição feita por especialistas e representantes da comunidade universitária que estiverem presentes no encontro, a declaração destaca o compromisso de fazer com que o sistema europeu de ensino superior exerça uma atração mundial em consonância com suas tradições culturais e científicas. Para tanto, são estabelecidas as seguintes metas para o Processo de Bolonha:

\section{QUADRO 2 - Metas do Processo de Bolonha}

\begin{tabular}{|c|}
\hline $\begin{array}{l}\text { Adoção de um sistema de diplomas facilmente compreensíveis e } \\
\text { comparáveis. }\end{array}$ \\
\hline $\begin{array}{l}\text { Adoção de um sistema baseado sobre dois ciclos principais, a graduação } \\
\text { e a pós-graduação (incluindo mestrado e doutorado), assegurando aos } \\
\text { estudantes um nível de qualificação apropriada para a inserção no mercado } \\
\text { de trabalho. }\end{array}$ \\
\hline $\begin{array}{l}\text { Estabelecimento de um sistema de créditos como o meio apropriado para } \\
\text { promover a mobilidade dos estudantes. (Tendo como exemplo o sistema } \\
\text { ECTS de transferência de créditos). }\end{array}$ \\
\hline $\begin{array}{l}\text { Promoção da mobilidade para estudantes, professores e pesquisadores } \\
\text { ultrapassando os obstáculos da livre circulação, com atenção particular } \\
\text { para as possibilidades de formação para os estudantes e o reconhecimento } \\
\text { dos períodos de pesquisa para os professores e pesquisadores. }\end{array}$ \\
\hline
\end{tabular}


Promoção da cooperação entre as instituições de ensino de superior com vistas a manter e garantir a qualidade do ensino europeu.

Promoção da dimensão europeia do ensino superior, essencialmente na elaboração de programas de estudo, na cooperação entre os estabelecimentos e programas integrados de estudo e pesquisa entre as universidades.

Fonte: declaração de Bolonha, 1999.

Para que as metas sejam alcançadas, os signatários comprometem-se com sua realização dentro das suas esferas de competência e pedem a cooperação permanente entre os Estados participantes e dos demais atores que passam a integrar esse processo.

\section{2 - A Declaração de Praga - 2001.}

Neste encontro, juntaram-se aos 29 Estados representados em Bolonha a Croácia, Chipre e Turquia (COMMUNIQUÉ DE PRAGUE, 2001). No comunicado dessa conferência os ministros de educação europeus reforçam os seis objetivos estabelecidos na reunião anterior, em Bolonha, e salientam outros pontos importantes ${ }^{13}$. Um dado importante foi a elaboração do "Furthering the Bologna Process" (2001), redigido pelo grupo de acompanhamento estabelecido para acompanhar o desenvolvimento dos objetivos colocadas consensualmente na Declaração de Bolonha, dois anos antes.

De fato, a decisão foi tomada pelos Ministros da União Européia em encontro em setembro de 1999 quando decidiram formar dois grupos para acompanhar o processo, o primeiro, restrito aos representantes estatais do processo e responsável pelo andamento do processo, o segundo apresenta-se como um grupo de acompanhamento constituído pelos países signatários além da Comissão Européia, Confederação de Reitores de Universidades

${ }^{13}$ National Academic Recognition Information Centres, criado por iniciativa da Comissão Europeia na década de 80. 
Europeias e a Associação Europeia de Universidades (Furthering the Bologna Process, 2001). São novos atores que entram na dinâmica de interação da construção da política pública internacional. Os estudantes se fazem ouvir depois da Convenção dos Estudantes Europeus realizada na Suécia, nesse mesmo ano, onde foram feitas recomendações levadas para o encontro. Além disso, foi criada a ENQA - European Association for Quality Assurance in Higher Education - que se incorpora ao Processo de Bolonha.

Com relação aos seis objetivos colocados pelo Processo de Bolonha destaca-se a recomendação para as universidades utilizarem parte da legislação já existente naquilo que concerne a validação internacional dos diplomas ${ }^{14}$. A adoção do sistema fundamentado nos dois ciclos principais foi alvo de debates com relação a preocupação dos programas conservarem suas diferentes orientações a fim de responder as distintas necessidades de formação. Com relação ao estabelecimento do sistema de créditos transferíveis, segue o apoio ao sistema ECTS, que terá como consequência a melhoria do acesso dos estudantes ao mercado de trabalho europeu, reforçando a competitividade e atratividade do sistema europeu de ensino superior. A mobilidade continua sendo vista como um objetivo importante e de consenso, embora existam obstáculos inúmeros, desde o reconhecimento dos estudos até a obtenção de vistos. Ressaltou-se a necessidade de promover a dimensão europeia no âmbito do ensino superior, através da realização de disciplinas e orientações que a contemplem nos estudos e pesquisas futuras.

Com relação ao seguimento do Processo de Bolonha confirma-se a criação de um grupo de acompanhamento e de um grupo preparatório. O primeiro será composto por representantes dos signatários e da Comissão Europeia e presidido por aquele que exerce a presidência da União Europeia. O segundo reunindo representantes dos países organizadores dos encontros (do que organiza a edição atual e do que organizará a seguinte),

${ }^{14}$ European Network of Information Centres, estabelecido pelo Conselho Europeu e pela UNESCO quando da Convenção de Lisboa. 
dois representantes de Estados membros e dois de Estados não membros da União Europeia e ocupa a presidência o Estado que abrigará o próximo encontro. Finalmente, coloca-se a organização representante das universidades e aquela representando os estudantes - EUA e ESIB como consultores dos trabalhos do grupo de acompanhamento, assim como o Conselho Europeu e a Associação Europeia de Estabelecimentos de Ensino Superior EURASHE.

\section{3 - A Declaração de Berlim - 2003}

Nova conferência com a presença de Ministros representando 32 países, realiza-se em Berlim, com o objetivo de se fazer um resumo dos progressos feitos até então, definir as prioridades e novos objetivos, e também para acelerar o estabelecimento do Espaço Europeu de Ensino Superior. O pragmatismo das metas estabelecidas divide espaço com a afirmação das ações valorativas relativas a melhoria das características sociais desse espaço e com a preocupação na preservação cultural dos Estados signatários. A relação com as instituições da União Europeia mantém sua proximidade segundo expressa o comunicado conjunto de Berlim. As considerações feitas pelo Conselho Europeu em Lisboa e Barcelona, nos anos de 2000 e 2002 respectivamente, da necessidade de se fazer da Europa uma economia do conhecimento competitiva e dinâmica passam pelo fortalecimento do Processo de Bolonha. Os grupos de acompanhamento e trabalho, estabelecidos no encontro anterior em Praga (2001) realizaram suas tarefas através da elaboração de relatórios e seminários no intervalo entre os encontros de 2001 e 2003.

Reconhece-se, da mesma forma, os esforços produzidos por outras organizações parceiras no Processo de Bolonha, através da realização de encontros e da elaboração de relatórios e recomendações para o avanço do processo. Cita-se, em particular, as contribuições da EUA (representando as universidades), da ESIB (representando os estudantes) e da EURASHE (representante os estabelecimentos de ensino superior da Europa). Constam 
como convidados para a conferência representantes do Comitê de Acompanhamento do Espaço Comum de Ensino Superior de União Europeia - América Latina e Caribe (UEALC). Na parte relacionada aos avanços estabelecidos dentro do Processo de Bolonha, enfoca-se inicialmente a questão da garantia de qualidade do ensino. A garantia depende tanto das ações estatais quanto dos planos desenvolvidos pelas próprias universidades dentro de sua autonomia.

Estabelecem-se metas a serem cumpridas pelos sistemas nacionais de garantia de qualidade até o próximo encontro, que aconteceria no ano de 2005, as seguintes ações: (1) definição de responsabilidades das instituições envolvidas, (2) uma política de avaliação dos programas e dos estabelecimentos de ensino superior incluindo tanto a avaliação interna quando exames externos e divulgação pública desses resultados, contando ainda com a participação dos estudantes nessa área, (3) um sistema de créditos, certificação ou de processos comparáveis e, por último (4) a participação e cooperação em redes internacionais. Nesse ponto pede-se o auxilia e a participação da ENQA, EUA, EURASHE E ESIB, garantindo assim a participação das organizações representativas dos principais atores envolvidos nesse processo.

Com relação a estrutura e reconhecimento dos diplomas trabalha-se com a ideia do estabelecimento de dois ciclos. Tornase tarefa delegada aos Estados membros a criação de um quadro comparável e compatível de qualificações que devem ser descritos de forma a contemplar, de maneira clara, a carga de trabalho, os níveis específicos, os resultados de formação e competências adquiridas assim como o perfil das qualificações, seguindo os acordos previamente estabelecidos. Sobre as metas referentes ao estabelecimento de um sistema de créditos transferíveis, frisa-se, novamente, o papel a ser desempenhado pelo ECTS, visto que esse sistema tem se tornado, cada vez mais, como a base de dados para os sistemas nacionais de créditos. Naquilo que se refere a adoção de um sistema de diplomas facilmente compreensíveis e comparáveis, continua-se a estimular o uso dos sistemas ENIC e NARIC. Instituise também a meta para que em 2005, os estudantes que terminem 
seus estudos de graduação possam receber, sem custos e de forma automática, o Suplemento do Diploma ${ }^{15}$, que deve ser redigido em uma língua que seja de uso corrente no continente europeu. Sobre os estabelecimentos de ensino superior, de origem privada e, por consequência, fora da esfera de intervenção e ação diretas do Estado ${ }^{16}$, recomenda-se que façam os esforços necessários para se enquadrarem nas diretrizes estabelecidas pelo Processo de Bolonha.

A participação dos estudantes no desenvolvimento para a realização do Espaço Europeu de Ensino Superior é destacada nesta conferência. Segundo o Comunicado de Berlim (2003), estudantes são colocados como parceiros integrais naquilo que os ministros signatários do comunicado designam como "governança do ensino superior". A escolha do termo revela um aspecto importante da ação dos atores estatais envolvidos; a necessidade de reafirmar o Processo de Bolonha como uma forma de interação mais democrática e distinta das políticas públicas estabelecidas e vistas apenas com a ação do Estado.

Entre os desenvolvimentos complementares que constam do Comunicado (2003), dois deles são destacados. Em primeiro lugar há a questão relativa ao estabelecimento do sistema de dois ciclos compreensíveis e comparáveis dentro do Espaço Europeu de Ensino Superior. Nesse ponto coloca-se a necessidade de se fazer concreto também um Espaço Europeu de Pesquisa. Decide-se então

15 “O Suplemento ao Diploma é um documento complementar do diploma que é conferido no final de um programa de estudos e em que consta a descrição do sistema de ensino superior do país de origem do diploma, caracterizando a instituição que ministrou o ensino e que conferiu o diploma, a formação realizada e o seu objectivo, providenciando, igualmente, informação detalhada sobre a formação realizada e os resultados obtidos. É emitido obrigatoriamente e de forma gratuita sempre que um diploma é outorgado.

${ }^{16}$ Como já exposto anteriormente, as universidades européias são públicas, em sua grande maioria. Nos documentos próprios do Processo de Bolonha o termo usado para fazer referencia ao que aqui chamaríamos de universidade privada é "établissement d'enseignement superieur" ou em inglês "higher education institutions". 
a incorporação do doutorado nos ciclos de aprendizado, adotandose o sistema 3-2-3 (graduação, mestrado e doutorado). O segundo diz respeito ao grupo de acompanhamento, do qual passam a integrar a ESIB e a UNESCO/CEPES. Finalmente, o Comunicado de Berlim confirma a aceitação dos novos Estados membros do Processo de Bolonha: Albânia, Andorra, Bósnia-Herzegovina, do Estado do Vaticano, da Rússia, Sérvia e Montenegro e da Macedônia. Desta forma o Processo para a contar, nessa data, com 40 membros.

\section{4 - A Declaração de Bergen - 2005}

Na Conferência realizada na cidade de Bergen, Noruega, no ano de 2005, o comunicado feito pelos ministros revela-nos importantes avanços. Em primeiro lugar, o grupo de Estados signatários do Processo de Bolonha aumentou com a entrada da Armênia, Azerbaijão, Geórgia, Moldávia e Ucrânia. Sublinhase o papel que tem sido desempenhado pelos demais atores na construção desse projeto, basicamente as universidades e demais estabelecimentos de ensino superior (e seus respectivos funcionários) e dos estudantes (Comunicado de Bergen, 2005 ${ }^{17}$ ).

${ }^{17}$ Ao longo do seu desenvolvimento, o Processo de Bolonha gradualmente adquire uma dinâmica própria, constituída por seus atores. Da primeira declaração dos quatro Ministro de Estado feita na Sorbonne a Declaração de Bergen percebe-se que a construção do Processo constitui uma rede de interações que perpassa os espaços subnacionais, nacionais e internacionais e integra atores estatais, privados, organizações sociais e envolve organizações internacionais. Conforme se integram como atores do Processo de Bolonha, estudantes e universidades encontram seus objetivos e valores de ação dentro dessa interação na medida em que desenvolvem seu próprio referencial. Exemplos dessa participação estão expressos nos relatórios de acompanhamento do biênio 2003-2005 desenvolvidos pelas EUA, por parte das universidades, e pela EISB (futura ESU), por parte dos estudantes universitários europeus. Há também, obviamente, o relatório elaborado pelo próprio grupo de acompanhamento, do qual fazem parte essas duas organizações internacionais. 
Reafirma-se o quadro global de qualificações para os três ciclos $(3+2+3)$ respeitando os ciclos intermediários de cada sistema nacional. Coloca-se o objetivo de elaboração de quadros nacionais de qualificações que sejam compatíveis para a efetivação do EHEA para o ano de 2010, com a supervisão do grupo de acompanhamento. A complementaridade com a educação continuada continua sendo uma preocupação expressa no comunicado. Com relação a qualidade de ensino, estimula-se a integração maior da ENQA no processo em parceria com as demais organizações e instituições participantes. Naquilo que concerne a reconhecimento dos diplomas e dos períodos de estudos, percebeu-se que 36 dos 45 países participantes ratificaram a Convenção de Lisboa sobre o Reconhecimento. A tomada como referência do sistema de reconhecimento continua sendo àquela desenvolvida pelas redes ENIC e NARIC.

No quadro colocado como Outros desafios e Prioridades, destacam-se as relações que devem ser estabelecidas e reforçadas entre o Espaço Europeu de Ensino Superior e o Espaço Europeu de Pesquisa, a dimensão social do Processo de Bolonha, a questão da mobilidade de estudantes e docentes, e ainda a questão de melhorar a atratividade do ensino superior europeu e como esse objetivo pode ser estabelecido através de diferentes formas de cooperação com outras regiões do globo.

Coloca-se também em evidência a necessidade de medidas visando a ajuda financeira aos estudantes através de programas de bolsas de estudo e de orientação acadêmica. O sistema de bolsas é também um aspecto importante para a concretização da mobilidade de estudantes e docentes dentro do Espaço Europeu de Ensino Superior, por isso torna-se necessário a implementação de um programa de bolsas e auxílios de pesquisa voltados para os docentes e pesquisadores. Com relação a atratividade do Espaço Europeu de Ensino Superior, os Ministros reafirmam a necessidade de um fortalecimento dos laços de cooperação com outras regiões do mundo assim como também reafirmam a necessidade de que o Processo de Bolonha seja melhor compreendido em outras áreas e continentes. 
Ao grupo de acompanhamento é destinada a tarefa de expandir os trabalhos de resumo e síntese dos resultados para seu próximo relatório a ser colocada na reunião do Ministros, que ocorrerá em Londres. Esse relatório deve-se basear na metodologia adequada nas questões relativas ao sistema de diplomas, na garantia de qualidade e no reconhecimento dos períodos de estudo e de diplomas. Especial atenção deve ser dada aos seguintes assuntos: (1) implementação de linhas de orientação para a garantia de qualidade, segundo os parâmetros fornecidos pela ENQA, (2) implementação dos quadros nacionais de qualificações, (3) reconhecimento dos diplomas conjuntos, inclusive do nível de doutorado e (4) criação de caminhos flexíveis de formação no ensino superior.

Finalmente, são colocados os novos membros consultivos do grupo de acompanhamento do Processo de Bolonha: A Estrutura Pan-europeia da Internacional da Educação (EI), a Associação Europeia para a Garantia de Qualidade no Ensino Superior (ENQA) e a União das Confederações dos Trabalhadores e das Indústrias da Europa (UNICE).

\section{5 - A Declaração de Londres - 2007}

Realizou-se em Londres, Inglaterra, o quinto encontro dos Ministros responsáveis do ensino superior dentro do Processo de Bolonha. Desta vez há a inclusão de apenas um novo membro Montenegro, que, na verdade já fazia parte dos acordos no âmbito do Processo de Bolonha, mas em conjunto com a Sérvia. Em seu Comunicado conjunto, sintetizam as ações de desenvolvimento visando o estabelecimento do Espaço Europeu de Ensino Superior (Communiqué de Londres, 2007).

Reafirma-se, como nos comunicados anteriores, a importância da liberdade e da autonomia universitária, sobre os princípios democráticos que regem o Processo de Bolonha e a preocupação sobre a inserção profissional dos estudantes universitários e sobre a atratividade e competitividade que devem se tornar características marcantes do ensino superior europeu. 
Coloca-se de forma mais clara a questão do papel que terá esse espaço com relação aos desafios da mundialização (termo utilizado poucas vezes nos comunicados anteriores, embora sempre tenha lhe sido feita referência de forma indireta ou implícita).

O papel de condutores do Processo de Bolonha não se configura apenas pelo papel assumido na redação das propostas a serem implementadas, ou pela responsabilidade de implementação nacional das decisões realizadas na esfera internacional que cabe a cada um dos Estados signatários, mas também pelas ações que visam garantir que outros atores envolvidos no Processo tenham as condições de cumprir as metas e objetivos que lhes são estipulados e acordados. Cabe aos Estados garantirem, por exemplo, as condições mínimas para o funcionamento adequado das universidades para que possam cumprir suas funções ligadas ao ensino e a pesquisa, e dentre essas condições, uma das mais importantes é a questão do financiamento, visto que a maioria das universidades europeias se constitui de instituições públicas.

A mobilidade de estudantes e docentes demonstra, segundo o comunicado (2007), avanços satisfatórios, porém resta ainda uma série de obstáculos a serem superados pelas ações dos atores envolvidos, como as questões de imigração, falta de auxílios financeiros, reconhecimento dos diplomas e as disposições sobre os sistemas de aposentadoria e contribuição dos docentes envolvidos no processo. A inserção no mercado de trabalho dos formados é alvo de preocupação e destaca-se a necessidade de uma melhor adaptação do ensino superior e o sistema de ciclos adotado.

O reconhecimento dos diplomas e qualificações do ensino superior continua sendo medida de acordo com os parâmetros estabelecidos dentro da Convenção entre o Conselho da Europa e a UNESCO - Convenção de Lisboa sobre o Reconhecimento de Diplomas. Dos 46 Estados atuantes dentro do Processo de Bolonha, 38 já haviam ratificado essa convenção quando do encontro de Londres, em 2007. Há uma especial demanda para que o grupo de acompanhamento - BFUG (Bologne Follow-up Group)- trabalhe em parceria com a rede ENIC/NARIC na análise dos planos nacionais e na difusão de boas práticas. A estrutura das 
qualificações (ou quadro de qualificações, referentes aos diplomas, títulos ou certificações de ensino superior) é o instrumento que facilita a realização das comparações dos diplomas dentro do Espaço Europeu de Ensino Superior e tem o objetivo de subsidiar as universidades na formação dos seus programas de ensino e sistema de créditos dentro das diretrizes do Processo de Bolonha. Essa estrutura de qualificações foi definida no encontro anterior e faz com que seja necessário que a estruturas nacionais de qualificações sejam concebidas dentro do quadro geral de qualificações definidos no âmbito definido do Espaço Europeu de Ensino Superior. Da estruturação desses quadros depende a questão da mobilidade dentro do processo.

Sobre a garantia da qualidade do ensino constata-se um avanço na maioria dos países devido a adoção, em Bergen 2005, dos padrões e linhas de orientação europeias para a garantia de qualidade dentro do Espaço Europeu de Ensino Superior. A evolução desse aspecto constituinte do Processo de Bolonha deve-se, em grande parte, aos trabalhos desenvolvidos a partir da realização do Primeiro Fórum Europeu de Garantia da Qualidade, organizado pela EUA, ENQA, EURASHE e ESIB (Chamados de Grupo E4). Esse exemplo demonstra como a dinâmica de interação dos atores envolvidos no Processo de Bolonha, tomado como exemplo de política pública internacional, descobre seus próprios caminhos de ação conforme o desenvolvimento os confronta com novos problemas a serem resolvidos.

Sobre as relações com o Espaço Europeu de Pesquisa os problemas levantados referem-se as regulações do ciclo de doutorado. Os Ministros demonstram preocupação no fortalecimento das atividades de pesquisa no Espaço Europeu de Ensino Superior. Cabe as universidades reforças seus esforços para o aumento das formações doutorais e para o estabelecimento de programas e perspectivas de pesquisa que se adéquem ao número maior de doutores.

A dimensão social continua a ser estimulada pelo Comunicado, muito embora não sejam colocados exemplos de maiores ações nessa área. A confirmação desse déficit de ações 
se expressa pelo uso contínuo dos verbos no condicional dentro do Comunicado de Londres. Ressalta-se também a preocupação exposta para o desenvolvimento para além do ano de 2010, que foi estabelecido como data limite para implementação das diretrizes do Processo de Bolonha. O ano de 2010 deve marcar, assim, a passagem do Processo de Bolonha para o Espaço Europeu de Ensino Superior. A reflexão sobre as perspectivas para além do ano de 2010 ficam a cargo do grupo de acompanhamento - BFUG.

\section{6 - A Declaração de Leuven e Louvain-la-neuve - 2009.}

Na última conferência antes do prazo estipulado para a implementação do Espaço Europeu de Ensino Superior, realizada em Leuven e Louvain-la-neuve, Bélgica, em abril de 2009, os representantes e ministros dos 46 países membros reafirmaram os principais objetivos do processo e traçaram os planos e estratégias para os próximos anos. Há duas mudanças básicas de tom com relação as declarações e comunicados anteriores: a crise econômica internacional iniciada no ano anterior se faz sentir no conteúdo do comunicado através da preocupação com o financiamento público do ensino superior e no papel que esse setor pode desempenhar em busca de saídas para a recém iniciada crise.

O Comunicado destaca que dez anos após a Declaração de Bolonha, o Processo construiu uma rica dinâmica de interações baseada em seus princípios gerais e trouxe para o cenário internacional a elaboração das políticas públicas de ensino superior, envolvendo os diversos atores a elas ligados. Foram muitos os avanços na questão de compatibilidade e comparabilidade dos diplomas, as ações em prol da mobilidade de estudantes e docentes, a criação da estrutura de diplomas baseada nos três ciclos, a própria visibilidade internacional do sistema europeu de ensino superior se modificou, a adoção de linhas de orientação europeias para a garantia da qualidade do ensino. Nota-se também uma mudança com relação aos objetivos e metas, visto que a estrutura do comunicado não se faz sobre as metas atingidas ou sobre o andamento dos processos de implementação estabelecidos, mas 
se debruça sobre as perspectivas que devem ser colocadas para a próxima década dentro do Espaço Europeu de Ensino Superior (COMMUNIQUE de LEUVEN et LOUAIN-LA-NEUVE, 2009).

Sobre a dimensão social é exposta a visão de que os sistemas de ensino superior devem refletir a variedade e diversidade das suas populações. Especial atenção deve ser dada para os grupos sociais que se encontram sub-representados dentro do ensino superior, e para isso recai sobre os Estados a responsabilidade de fornecer as condições adequadas para que tal objetivo se realize. Sobre os programas de educação continuada coloca-se a necessidade de um maior desenvolvimento dos quadros nacionais de qualificação. A inserção no mercado de trabalho (employability) é citado como meta para o próximo decênio, mas não há a inserção de objetivos mensuráveis para um prazo pré-estabelecido. O objetivo principal é fazer com que a estrutura do ensino superior e seu funcionamento sejam eficazes na orientação de carreira dos estudantes e na formação adequada aos novos conhecimentos por parte da força de trabalho.

Ressalta-se também a aprendizado centrado no estudante como uma missão a ser cumprida pelas universidades. O Comunicado dos Ministros deixa transparecer que a estrutura de ciclos adotada pelas universidades ainda se encontra distante do ideal pensado pelos condutores do Processo de Bolonha. Os três ciclos foram estabelecidos, mas seu conteúdo necessitaria de reformas e adequações. As universidades devem se enquadrar nas linhas de orientação europeias para a garantia da qualidade de ensino.

O Comunicado revela também uma preocupação para com o aumento do número de doutores dentro do Espaço Europeu de Ensino Superior. Esse objetivo requer a ação direta das universidades pautando seus programas de pesquisa pela interdisciplinaridade e pela existência de programas transversais, abarcando várias áreas de conhecimento. Por outro lado, constatase que o desenvolvimento da carreira de pesquisador deve se tornar mais atrativa para os estudantes. 
Sobre a Mobilidade, o Comunicado reforça suas qualidades intrínsecas, como a melhora da qualidade das formações superiores, a possibilidade de melhor inserção no mercado de trabalho, estimula a convivência entre diferentes culturas, encoraja a pluralidade linguística, e faz crescer os laços entre as universidades europeias. Os Estados devem se comprometer a consolidar esse processo, de acordo com metas estabelecidas pelo Processo de Bolonha para 2020. A mobilidade deve contemplar condições acessíveis aos estudantes e também favoráveis para o deslocamento dos docente o que implica em uma série de medidas processuais que devem ser adotadas pelos Estados e universidades que escapam do campo do ensino superior, tornando-a um dos elementos de maior complexidade para sua implementação.

O Comunicado concentra-se também na questão sobre uma mais efetiva coleta e compartilhamento dos dados dos atores envolvidos no Processo de Bolonha. Os dados referemse à mobilidade, a dimensão social do programa, a inserção no mercado de trabalho dos estudantes, e outras áreas. De maneira semelhante é feita a observação sobre as informações que as universidades devem fornecer sobre seus cursos e programas, e suas especialidades. Essa troca de informações deve trazer maior transparência multidimensional e condições de comparação dos dados ao Espaço Europeu de Ensino Superior e deve contar com a participação das organizações europeias de estudantes e universidades. Reafirmou-se que o financiamento público continua sendo a expressão da sua responsabilidade junto as universidades.

De acordo com a visão dos Ministros responsáveis pelo ensino superior a estrutura organizacional do Processo de Bolonha mostrou-se adequada ao longo da sua primeira década de funcionamento. Coloca-se apenas uma pequena mudança para o futuro que aproxima o Processo de Bolonha da União Europeia, já que a partir de então sua condução deverá ser compartilhada entre o país responsável pela presidência da UE e um país que dela não faz parte. Sobre o grupo de acompanhamento (BFUG - Bologna Follow-up Group), foram estabelecidas as seguintes funções para o encontro de 2012 (IDEM): (1) definir os indicadores utilizados 
para mensurar e seguir a mobilidade de estudantes e docentes e a dimensão social do processo, paralelamente as coletas de dados, (2) refletir sobre uma forma de obter uma mobilidade equilibrada dentro do Espaço Europeu de Ensino Superior, (3) acompanhar o desenvolvimento dos mecanismos de transparência e prestar contas dessa ação quando da Conferência Ministerial de 2012, (4) estabelecer uma rede, utilizando-se de forma ótima as estruturas já existentes, que melhorará a informação sobre o Processo de Bolonha e dele fazer melhor promoção externa e (5) acompanhar as recomendações relativas a análise dos planos de ação nacionais sobre o reconhecimento de diplomas.

Já com relação aos relatórios de avanços para a implementação das decisões do Processo de Bolonha, eles devem seguir as seguintes orientações: (1) $\mathrm{O}$ inventário deve apurar sua metodologia fundada sobre fatos e números (evidence-based methodology), (2) Eurostat e Eurostudent em cooperação com Eurydice devem colaborar na coleta de dados pertinentes, (3) a prestação de contas deve ser supervisionada pelo grupo de acompanhamento (BFUG), (4) cabe ao E4 (ENQA-EUA-EURASHE-ESU) avançarem no desenvolvimento da dimensão europeia de garantia de qualidade e de prestarem especial atenção para que o Registro Europeu de Agencias de Garantia de Qualidade seja avaliado externamente, considerando-se os pontos de vista dos participantes.

\section{7 - A Declaração de Budapeste-Viena - 2010.}

O dia 12 de março de 2010 marca o lançamento do Espaço Europeu de Ensino Superior, como objetivara a Declaração de Bolonha, feita 11 anos antes. Com a recente entrada do Cazaquistão, são agora 47 os Estados participantes. Passou-se uma década de construção de uma política pública onde participaram vários atores agindo e interagindo entre os níveis subnacionais, nacionais e internacionais. Os objetivos traçados de início levaram a uma participação maior de atores, estatais, privados, intermediários e sociais, que influenciaram (e continuam a influenciar) 
a implementação desses objetivos assim como suas mudanças ao longo dos anos passados.

Nesse sentido o Comunicado (DECLARATION DE BUDAPEST-VIENNE, 2010) evoca, corretamente, o adjetivo "único" para descrever a parceria que se estabeleceu entre atores distintos em níveis distintos da polícia pública. Confiança, cooperação e respeito as diversidades dos atores não se constituem apenas em qualificações próprias de um comunicado feito pelos atores estatais, elas representam valores que serviram de base para o desenvolvimento do processo.

Contudo, o desenvolvimento e evolução que se deram em diferentes níveis de acordo com os objetivos estabelecidos quando do seu lançamento. Segundo os relatórios feitos pelo grupo de acompanhamento percebe-se uma maior assimilação do Processo de Bolonha na comunidade acadêmica mas percebese também que as linhas de ação do EHEA, como a reforma dos diplomas e programas de estudo, a garantia da qualidade, as ações de reconhecimento, mobilidade e a dimensão social foram implementadas em proporções diversas e irregulares entre os signatários (IDEM, 2010). Avanços em graus diferentes como demonstram os "Stocktaking reports - Report from working groups appointed by the Bologna Follow-up Group" dos anos de 2005, 2007 e 2009. Cada um desses levantamentos feitos pelos grupos de trabalho elabora uma visão global do andamento do Processo de Bolonha, assim como também demonstra a situação em cada Estado, de acordo com o grau de implementação das ações previstas.

Entre as mudanças e transformações ao longo do Processo, há também as mudanças do contexto externo a interação que acabam por colocar novos desafios e novas respostas aos atores participantes. A crise econômica global que se inicia no final de 2008 se acentua nos anos subsequentes e traz fortes consequências econômicas, políticas e sociais para os Estados europeus. As decisões de austeridade fiscal e monetária são seguidas de protestos e contestação em grande parte dos países, e muitas dessas manifestações envolveram os atores participantes na dinâmica do 
Processo de Bolonha. Mudanças de contexto trazem mudanças na percepção dos atores.

A ação de interação para intensificar os esforços para a realização das reformas necessárias para a implementação das metas estabelecidas ocorre dentro dos contornos do cenário internacional, envolvendo, também, atores nacionais e subnacionais. Por outro lado, releva-se no plano nacional a importância da ação dos atores estatais para que façam valer os compromissos assumidos na implementação das metas acordados. Reconhecendo a importância da manutenção da liberdade acadêmica e da importância da comunidade acadêmica no desenvolvimento do Processo de Bolonha, os Ministros destacam também a importância de um ambiente propício para o cumprimento das decisões tomadas. $\mathrm{O}$ papel do pessoal administrativo foi, pela primeira vez, colocado em destaque pelo Comunicado dos Ministros (IDEM). Soma-se ao reconhecimento da importância do pessoal administrativo aquele da maior participação dos estudantes, não apenas através da sua entidade representativa europeia no grupo de acompanhamento (BFUG), mas também como partes integrantes da estrutura de decisão, em suas diversas dimensões: europeia, nacional e local.

A crise econômica volta à pauta do Comunicado dos Ministros quando da reafirmação do dever público com relação ao ensino superior. A ênfase dada à responsabilidade pública liga-se a própria responsabilidade dos Ministros e das suas interações políticas em seus respectivos Estados, porque cabe a eles a responsabilidade (ou a maior parte da responsabilidade) de garantir a manutenção dos investimentos públicos nas universidades. Trata-se, aqui, da própria legitimação da ação dos atores estatais dado suas relações de poder e interação com os outros atores estatais envolvidos.

Por fim, os Ministros reforçam o pedido feito ao grupo de acompanhamento (BFUG) para que proponha medidas e ações que facilitem a implementação completa dos objetivos colocados como metas para o Processo de Bolonha no nível nacional e nas próprias universidades para o bom desenvolvimento dos métodos de trabalho e compartilhamento das informações. 


\section{Conclusões - As Declarações pelas teorias cognitivas das políticas públicas}

A análise do desenvolvimento do Processo de Bolonha até a instituição oficial do Espaço Europeu de Ensino Superior foi feita através das declarações e comunicados das reuniões dos ministros responsáveis por tal área nos países signatários. A escolha por esse caminho justifica-se por mostrar a visão dos atores centrais dessa ação, os ministros que representam o poder estatal ou o "Estado em Ação", e como se construíram suas decisões e sua dinâmica de interação interna e com os demais atores que se juntam ao processo. Pela complexidade do tema seria possível outras formas de acompanhamento da sua evolução, como os comunicados das instituições europeias representantes das universidades ou dos estudantes, ou ainda pela visão da União Europeia, mas optou-se aqui pelas declarações oficiais dos representantes do Estado.

De acordo com as teorias cognitivas das políticas públicas é possível realizar a seguinte leitura da evolução do Processo de Bolonha até a criação oficial do Espaço Europeu de Ensino Superior: trata-se de uma política pública internacional que se constrói através da dinâmica de interação entre seus atores constituintes envolvendo níveis diferentes de ação que se entrelaçam: o internacional, o nacional e o local.

A relação setorial-global se faz em dois níveis; no primeiro há a interação na esfera internacional onde os atores estatais (os ministros responsáveis pelo ensino superior) interagem para atingirem um consenso, ainda que provisório, com relação ao andamento do Processo de Bolonha. Neste nível, o global configura-se como o próprio processo em sua dimensão internacional e o setorial é representado por cada Estado nela participante. No segundo nível há a relação entre as políticas nacionais de ensino superior e as demais políticas públicas de cada Estado. Aqui, a busca pela harmonização das ações decididas na esfera internacional precisa ser efetivada através da ação pública em diversas áreas: na regulação do sistema de ensino superior, nas regras que garantam a mobilidade de estudantes, pesquisadores 
e docentes, na interação com as políticas de ciência e tecnologia e mesmo na área de regulação do trabalho e do estudo dos estudantes e docentes que usufruem da mobilidade transnacional definida no próprio processo. Essa dupla regulação dentro de Estado e na esfera internacional convive ainda, em cada um dos constituintes, com as variações dos ciclos políticos internos.

O referencial dessa política pública internacional resulta da constante interação entre os atores envolvidos e os contextos políticos, sociais e econômicos onde se desenrolam. É possível perceber que o referencial parte da aprendizagem de experiências anteriores, como no caso dos acordos anteriores ao Processo de Bolonha no âmbito da União Europeia, dos compromissos de integração da universidades feito no final dos anos 1980, e do sistema de transferência de créditos. Por outro lado, o referencial se faz também através da busca pela solução de novos problemas que apenas podem aparecer com o desenvolvimento e implementação dessa política pública internacional, assim como dos novos atores que nela se incorporam. Novas ações são propostas, metas são revistas (como no caso dos ciclos do ensino superior em que se incorpora os estudos doutorais), e novas estruturas institucionais são criadas como resultado da dinâmica de ação da política pública, como o grupo de acompanhamento (BFUG). São novos atores que surgem como resultado do Processo de Bolonha e que, a partir de então, passam a influenciar seus rumos e diretrizes. A agenda das associações europeias de estudantes e universidades - ESU e EUA se modifica e se recria a partir dessas ações. As instituições, as ideias e os interesses são componentes complementares e fundamentais na construção permanente do referencial. São as variáveis que se entrelaçam e dão nova forma ao Processo de Bolonha que também marca a passagem dos ciclos de ação do Estado e das políticas públicas: do Estado regulador e empresarial para o ciclo da Governança Sustentável onde as ações se guiam pelo princípio de maior participação dos atores na condução da política pública (governança) e pelo entrelaçamento das dimensões internacionais, nacionais e locais na implementação, desenvolvimento e nas decisões que constituem a política pública. 


\section{Bibliografia}

COMMUNIQUÉ DE BERGEN. Bergen, 2005. Communiqué de la Conferénce de Ministres chargés de l'enseignement superieur. Disponível em http://www.europe-education-formation.fr/ docs/Bologne/Bergen-Communique--Version-finale--FR.doc Acesso em 14/07/2015.

COMMUNIQUÉ DE BERLIN, Berlim, 2003. Communiqué de la Conferénce de Ministres chargés de l'enseignement superieur. Disponível em http://www.bologna-bergen2005. no/Docs/France/030919_Berlin_Communique-Fr.pdf Acesso em 14/07/2015.

COMMUNIQUÉ DE LONDRES. Londres, 2007. Communiqué de la Conférence des Ministres européens chargés de l'Enseignement Supérieur, Londres, 17-18 Mai 2007. Disponível em: http://www.ehea.info/Uploads/ Documents/2007_London_Communique_French.pdf Acesso em 14/07/2015.

COMMUNIQUÉ DE LOUVAIN ET LOUVAIN-LA-NEUVE. Louvain, 2009. Communiqué de la Conférence des ministres européens chargés de l'Enseignement supérieur, Louvain et Louvain-la-Neuve, 28 et 29 avril 2009. Disponível em http://www.ehea.info/Uploads/Documents/2009_Louvain_ Louvain-la_Neuve_Communiqu\%C3\%A9_FR.pdf Acesso em 14/07/2015.

COMMUNIQUÉ DE PRAGUE. Praga, 2001. Communiqué de la conférence de Ministres chargés de l'enseignement supérieur. Disponível em http://www.ehea.info/Uploads/ Documents/2001_Prague_Communique_French.pdf . Acesso em 14/07/2015.

DÉCLARATION DE BOLOGNE. Bolonha, 1999. Disponível em http://www.ehea.info/Uploads/Documents/1999_Bologna_ Declaration_French.pdf, acesso em 11/07/2015. 
DÉCLARATION DE BUDAPEST-VIENNE SUR LL'ESPACE EUROPÉEN DE L'ENSEIGNEMENT SUPERIEUR. Budapeste-Viena, 2010. Disponível em http://www.ehea.info/ Uploads/Documents/2010_Budapest Vienna_Declaration_ FR.pdf Acesso em 14/07/2015.

DÉCLARATION DE LA SORBONNE, Paris, 1998. Disponível em http://www.ehea.info/Uploads/Documents/1998_Sorbonne_ Declaration_French .pdf , Acesso em 11/06/2015.

FRONZAGLIA, Maurício. Políticas Públicas Internacionais: o caso do Processo de Bolonha. Tese de doutorado defendida junto ao Departamento de Ciência Política da Universidade Estadual de Campinas. Campinas, 2011.

FURTHERING THE BOLOGNA PROCESS: Report to the Ministers of Education of the signatory countries Prague, May 2001. Disponível em http://www.ond.vlaanderen. be/hogeronderwijs/bologna/documents/GRP_for_MC/ LourtieReport-FromBolognatoPragueMay2001.pdf (acesso em 14/07/2015).

JACQUOT, Sophie et WOLL, Cornelia. "Action publique Européenne: les acteurs stratégiques face a l'Europe", Politique européenne 2/2008 ( $n^{\circ}$ 25), p. 161-192.

JOBERT Bruno (1985). “Une approche dialectique des politiques publiques", Pôle Sud 2/2004 (n²1), p. 43-54.

JOBERT, B. E MULLER, P. L'Etat en Action: politiques publiques et corporatismes. Paris, Presses Universitaires de France. 1987.

HASSENTEUFEL, Patrick. Sociologie Publique: l'Action Publique. Paris, Editions Armand Colin, 296 p. 2008.

HASSENTEUFEL, Patrick et SUREL, Yves. "Des politiques publiques comme les autres? Construction de l'objet et outils d'analyse des politiques européennes". Politique Européenne 2000/1, n⿳⺈ 1, p 8-24. 
KINGDON, John. "The Reality of Public Policy Making Ethical Dimensions of Health Policy", OXFORD University Press, pp. 97-116, 2002.

KOTT, Sandrine e DROUX, Jöelle ed. Globalizing Social Rights: The International Labour Organization and Beyond. Palgrave Macmillan, 2013.

LASSWELL, Harold. The Policy Sciences: Recent Developments in Scope and Method, Stanford University Press, pp. 3-15. 1951.

. "The emerging conception of the policy sciences", in Policy Sciences 1 (1), Spring, 1970. pp. 3-14.

MAGNA CHARTA UNIVERSITATUM, Bolonha, 1998. Disponível em: $\quad$ www.magna-charta.org/resources/files/the-magnacharta/portuguese. Acesso em 13/06/2015.

MAZMANIAN, D.Z. e SABATIER, P. A. Implementation and Public Policy. Glenview: Scott Foresman and Company, 1983.

MULLER, Pierre. 'Mise en perspective. Une théorie des cycles d'action publique pour penser le changement systémique' in L. Boussaguet, S. Jacquot, P. Ravinet and P. Muller Une French touch dans l'analyse des politiques publiques? Paris: Les Presses de Sciences Po, 405-435, 2015.

PALIER, Bruno e SUREL, Yves. "Les trois "i" et l'analyse de l'État en action". Revue Française de Science Politique, vol 55, nº 1, fev. 2005, pp. 7-32.

RADAELII, Claudio M. "Logiques de pouvoir et récits dans les politiques publiques de l'Union Européenne". Revue Française de Science Politique, Volume 50, № 02, 2000. p. 255-276.

SAURUGGERS. etSUREL.Y. “L'Européanisation comme processus de transfert de politique publique", Revue Internationale de politique comparée 2006/2, Volume 13, p. 179-211. 
$|100|$

O Processo de Bolonha...

SKOCPOL Theda. "Formation de l'Etat et politiques sociales aux Etats-Unis". In: Actes de la recherche en sciences sociales. Vol. 9697, mars 1993. pp. 21-37

SERBANESCU-LESTRADE, Karin. La mise en œuvre du Processus de Bologne en France et en Allemagne. THESE Pour obtenir le grade de DOCTEUR DE L'UNIVERSITE PARIS X- NANTERRE en Sciences de l'éducation. Paris, 2009.

SUREL, Yves. "L'Integration Européenne vue par l'approche cognitive et normative des politiques publiques". Revue Française de Science Politique, volume 50, no 02, 2000, p. 235-254. 